\title{
Café e saúde humana: um enfoque nas substâncias presentes na bebida relacionadas às doenças cardiovasculares $^{1}$
}

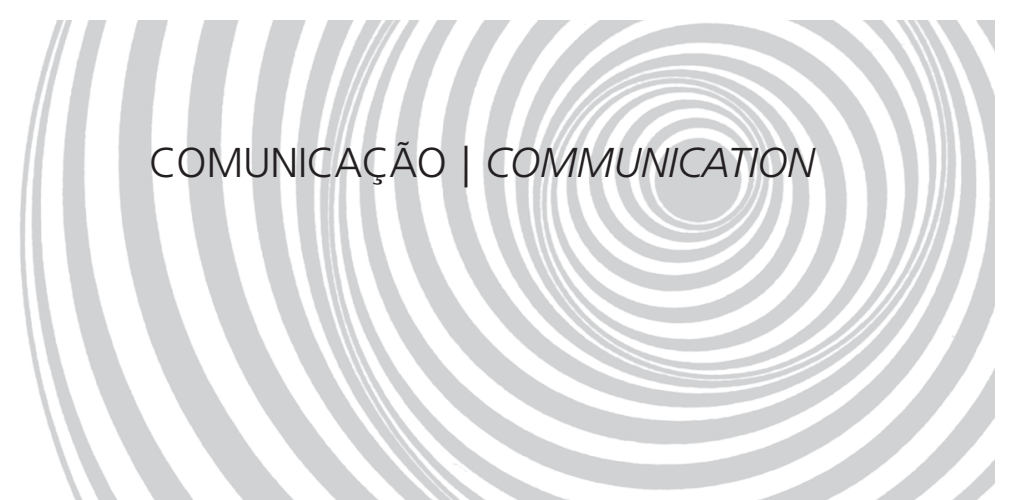

\author{
Coffee and human health: a focus on the \\ substances of the beverage related to \\ cardiovascular disease
}

Fabiana Accioly de LIMA2,3

Antônio Euzébio Goulart SANT'ANA ${ }^{4}$

Terezinha da Rocha ATAÍDE²

Cristhiane Maria Bazílio de OMENA ${ }^{4}$

Maria Emília da Silva MENEZES 4

Sandra Mary Lima VASCONCELOS2,3

RE S U M O

O café é a bebida mais consumida no Brasil e no mundo ocidental. O fato de ser uma bebida tão popular, aliado à sua importância econômica, explica o interesse por estudos sobre o café, desde a sua composição até seus efeitos na saúde humana. Dentre as diversas substâncias presentes na composição química do café, além dos nutrientes, destacam-se a cafeína, os diterpenos cafestol e kahweol e os ácidos clorogênicos, o que faz do café uma importante fonte dietética destes compostos. Muitos estudos têm verificado a influência de seus constituintes na saúde, principalmente a cafeína vs a elevação da pressão arterial; o cafestol e o kahweo/ vs a dislipidemia; e ácidos clorogênicos vs proteção cardiovascular, por suas propriedades antioxidantes. Este artigo tem como objetivo apresentar de forma sucinta a importância da bebida e sua composição química, os

\footnotetext{
1 Artigo elaborado a partir da dissertação de F.A. LIMA, intitulada "Consumo de café segundo métodos de preparo e associação com perfil lipídico sérico em hipertensos e diabéticos de Flexeiras - AL". Universidade Federal de Alagoas; 2008. Trabalho desenvolvido em projeto de pesquisa para o SUS (PPSUS/CNPq/FAPEAL), processo 007/2004-PPSUS-AL. Apoio: Fundação de Pesquisa do Estado de Alagoas, processo n 2005-0230427-7.

2 Universidade Federal de Alagoas, Faculdade de Nutrição, Programa de Pós-Graduação em Nutrição. Maceió, AL, Brasil.

${ }^{3}$ Universidade Federal de Alagoas, Faculdade de Nutrição, Laboratório de Nutrição em Cardiologia. Campus A.C. Simões, BR 104 Norte, km 97, Tabuleiro dos Martins, 57072-970, Maceió, AL, Brasil. Correspondência para/Correspondence to: S.M.L. VASCONCELOS. E-mail: <sandra-mary@hotmail.com>.

${ }^{4}$ Universidade Federal de Alagoas, Instituto de Química e Biotecnologia, Programa de Pós-Graduação em Química e Biotecnologia. Maceió, AL, Brasil.
} 
1064 F.A. LIMA et al.

mecanismos fisiológicos envolvidos na elevação da pressão arterial e do colesterol sérico atribuíveis ao café, bem como estudos selecionados que verificaram a associação do consumo da bebida com estas doenças cardiovasculares.

Termos de indexação: Ácidos clorogênicos. Café. Cafeína. Dislipidemias. Diterpenos. Hipertensão.

\section{A B S T R A C T}

Coffee is the most consumed beverage in the Western world, including Brazil. The fact that it is one the most popular beverages and its worldwide consumption and economic importance explain the interest for studies on coffee, from its composition to its effects on human health. In addition to the nutrients, its various components include caffeine, the diterpenes cafestol and kahweol, and chlorogenic acids, with coffee being an important dietary source of these compounds. Many studies have verified the association between its constituents and health, especially caffeine and high blood pressure, cafestol and kahweol and dyslipidemias, and chlorogenic acids and cardiovascular protection from their antioxidant properties. This article aims to succinctly present the importance and composition of the drink, the physiological mechanisms involved in the increased blood pressure and serum cholesterol attributed to coffee, and selected studies that verified the association between coffee consumption and these cardiovascular diseases.

Indexing terms: Chlorogenic acids. Coffee. Caffeine. Dyslipidemias. Diterpenes. Hypertension.

\section{N T R O D U Ç Ã O}

Estudos de identificação de substâncias presentes no café e da relação de muitas delas com a saúde vêm crescendo nas ultimas décadas $^{1-12}$. O fato de ser uma das bebidas mais populares, mundialmente consumida, bem como a sua importância econômica, explicam o interesse por estudos sobre a sua composição química e sobre os efeitos fisiológicos e fisiopatológicos dos seus constituintes ${ }^{13,14}$.

Existem diferentes maneiras (técnicas culinárias) de se preparar a bebida café, que variam conforme a tradição de cada país. No Brasil, as formas de preparo mais comuns são: café fervido ou estilo escandinavo (sem filtração do pó), filtrado (filtro de papel), café à brasileira (filtro de pano) e café expresso, além do uso do café instantâneo ou solúvel ${ }^{12}$. Alguns estudos verificaram a influência do modo de preparo da bebida sobre o perfil lipídico sérico 1,15-19.

Os objetivos deste trabalho são apresentar de forma sucinta a importância do café, e sua composição química, os mecanismos fisiológicos envolvidos na elevação da pressão arterial e do colesterol sérico atribuíveis ao café, estudos selecionados que verificaram se há associação do seu consumo de café com doenças cardiovasculares, bem como a bebida como fonte de antioxidantes da dieta

A estratégia de busca de artigos incluiu pesquisa em bases eletrônicas e busca de referências citadas nas publicações inicialmente selecionadas. Utilizaram-se as bases eletrônicas MedLine, PubMed, Bireme e, Periódicos-Capes, no período entre 1988 e 2008. As palavras "coffee", "caffeine", "diterpenes", "kaweol", "cafestol", "chlorogenic acids", "hypertension", "dyslipidemias" foram utilizadas como descritores. Foram incluídos artigos de revisão, estudos caso-controle, de coorte, randomizados e meta-análises envolvendo seres humanos.

A cafeína e os diterpenos cafestol e kahweol encontrados no café são compostos relacionados com Hipertensão Arterial Sistêmica (HAS), inflamação endotelial, Infarto Agudo do Miocárdio (IAM), Doença Arterial Coronariana (DAC), arritmias cardíacas, acidente vascular cerebral e dislipidemias ${ }^{1,16}$. A cafeína é a substância do café mais estreitamente relacionada com a Pressão Arterial (PA). Os diterpenos cafestol e kahweol, por sua vez, apresentam efeitos potencialmente hiperlipemiantes, especialmente sobre o colesterol plasmático. No entanto, além da cafeína e dos diterpenos, compostos com reconhecida ativi- 
dade antioxidante, o café é uma importante fonte de compostos fenólicos não flavonóides e compostos voláteis responsáveis pelo aroma, que tornam a bebida uma das maiores fontes de antioxidantes da dieta ${ }^{6}$. Apesar da dificuldade em se estabelecer uma associação mais conclusiva entre consumo de café e doenças cardiovasculares, provavelmente em função desses efeitos contraditórios, das diferentes formas de preparo da bebida e da quantidade consumida diariamente, o consumo moderado pode até mesmo ser recomendável, em virtude de um possível papel protetor sobre o risco cardiovascular.

\section{Composição química do café e relação de seus constituintes com a saúde humana}

A composição química do grão de café é influenciada pelos seguintes fatores: genética, sistema de cultivo, época de colheita, processo de manipulação e conservação do grão, armazenamento e torrefação. Essas variáveis determinam a qualidade do grão de café quanto à cor, ao aspecto, ao número de defeitos, ao aroma e ao sabor da bebida. No entanto, a composição química do grão varia principalmente em função da espécie, sendo este o fator primordial para que os grãos crus, quando submetidos a tratamento térmico, forneçam bebidas com características sensoriais diferenciadas ${ }^{13}$.

Dentre as várias espécies de café conhecidas, as comercializadas no Brasil e de maior importância econômica são Coffea arábica (originária do Oriente Médio) e Coffea canephora, variedade conillon, genericamente chamada de robusta (originária da África), que ocupam 74\% e $26 \%$, respectivamente, do parque cafeeiro brasileiro $^{13}$. Estes dois tipos podem ser usados individualmente ou combinados de diferentes formas. Combinados é a forma mais comercializada no Brasil, segundo a Associação Brasileira da Indústria do Café $(A B I C)^{20}$.

O sabor e o aroma da bebida café são altamente complexos, resultantes da mistura de vários constituintes químicos voláteis e não voláteis. Dentre tais compostos, 29 voláteis foram identi- ficados como os principais responsáveis pelo aroma característico do café torrado e moído ${ }^{21,22}$. O processo de torrefação origina profundas mudanças químicas na composição e atividade biológica do grão de café, de tal forma que o aroma da bebida está associado com a temperatura da torra. Durante a torrefação, reações simultâneas de Maillard (condensação da carbonila de um açúcar redutor com um grupamento $\alpha$-amino de um aminoácido), degradação de Strecker (reação entre $\alpha$-dicarbonilas e $\alpha$-aminoácidos), pirólise (desidratação térmica) e oxidação produzem um grande número de diferentes compostos voláteis (aldeídos, cetonas, alcoóis, éteres, hidrocarbonetos, ácidos carboxílicos, anidridos, ésteres, lactonas, compostos sulfurados, entre outros), de modo que mais de oitocentos compostos de várias classes já foram identificados ${ }^{14}$.

O conteúdo nutricional do pó de café torrado $^{23}$ está ilustrado na Tabela 1 . Além dos nutrientes, o café é rico em compostos bioativos, sendo os mais estudados: a cafeína (1,3,7-trimetilxantina), estimulante do sistema nervoso central (SNC) e do músculo cardíaco, os ácidos clorogênicos (cafeoilquínicos, dicafeoilquínicos, feruloilquínicos e p-cumaroilquínicos), que possuem atividade anticancerígena e propriedades antioxidantes, e os diterpenos cafestol e kahweol, relacionados com o metabolismo lipídico (dislipidemias). Estes compostos são os mais estudados devido as repercussões sobre a saúde humana de seus efeitos fisiológicos (Quadro 1)'1.

Tabela 1. Conteúdo nutricional em $100 \mathrm{~g}$ de café em pó torrado.

\begin{tabular}{lc}
\hline Nutriente & Quantidade \\
\hline Proteína $(\mathrm{g})$ & 15 \\
Carboidrato (g) & 66 \\
Lipídeos (g) & 12 \\
Cálcio (mg) & 107 \\
Magnésio (mg) & 165 \\
Fósforo (mg) & 169 \\
Ferro (mg) & 8,1 \\
Sódio (mg) & 1 \\
Potássio (mg) & 1609 \\
Cobre (mg) & 1,3 \\
Zinco $(\mathrm{mg})$ & 0,5 \\
\hline
\end{tabular}

Fonte: Núcleo de Estudos e Pesquisa em Alimentação ${ }^{23}$. 
Quadro 1. Substâncias presentes no café, estruturas químicas e mecanismos propostos de sua associação com enfermidades.

\begin{tabular}{lll}
\hline Substâncias & Mecanismos & Enfermidades \\
\hline Ácidos clorogênicos & Inibição da glicose-6-fosfatase & Diabetes mellitus tipo 2 \\
Inibição da absorção intestinal da glicose & Doença de Parkinson \\
Cafeína & Neurotoxicidade dopaminérgica protegida & Câncer cólon-retal \\
Cafestol e Kahweol & Diminuição da síntese e secreção de ácidos biliares & Aumento da enzima de fase II e da síntese de glutationa \\
Cafestol, kahweol, cafeína e áci- & Aumento da enzima de fase II e da síntese de glutationa & Injúria hepática, cirrose e carcinoma \\
do clorogênico & sintetase & Hepatocelular \\
& Aumento de LDL-c e colesterol-total & Doença cardiovascular \\
Cafestol, kahweol e cafeína & Elevação da pressão sanguínea & Osteoporose \\
Cafeína & Inibição da absorção do cálcio nos enterócitos & Deficiência de ferro \\
Ácidos clorogênicose outros & Inibição da absorção de ferro não heme nos enterócitos & \\
polifenóis & & \\
\hline
\end{tabular}

Fonte: Higdon \& Frei ${ }^{1}$.

Quadro 2. Estudos selecionados relacionando ingestão de café e níveis de pressão arterial sistêmica.

\begin{tabular}{|c|c|c|}
\hline Referência & n e tipo de estudo & Conclusão \\
\hline Birkett et al..$^{25}$ & $\begin{array}{l}2436 \text { adultos } \\
\text { Estudo randomizado }\end{array}$ & $\begin{array}{l}\text { Associação positiva, porém aumento pequeno da PAD } \\
(<1 \mathrm{mmHg}) \text {, o que não representa risco para HAS }\end{array}$ \\
\hline Stensvold et al. $J^{26}$ & $\begin{array}{l}14680 \text { H e } 14859 \text { M } \\
\text { Estudo randomizado, duplo cego (café fervido } \\
\text { versus filtrado) }\end{array}$ & $\begin{array}{l}\text { Associação negativa entre café filtrado e elevação da PAS, } \\
\text { PAD e HAS }\end{array}$ \\
\hline Jee et al. ${ }^{27}$ & $\begin{array}{l}522 \text { indivíduos } \\
\text { Meta-análise de } 11 \text { estudos randomizados }\end{array}$ & Efeito na elevação da PAS e PAD foi maior nos jovens \\
\hline Hartley et al. ${ }^{28}$ & $\begin{array}{l}182 \mathrm{H} \\
\text { Estudo randomizado } \\
\text { (PA normal e HAS) }\end{array}$ & $\begin{array}{l}\text { A PA aumentou em todos os grupos, especialmente no gru- } \\
\text { po hipertenso }\end{array}$ \\
\hline Klag et al. ${ }^{29}$ & $\begin{array}{l}1017 \mathrm{H} \\
\text { Estudo de coorte prospectivo acompanhado por } \\
33 \text { anos }\end{array}$ & $\begin{array}{l}\text { Apesar de entre os bebedores de café haver maior incidência } \\
\text { de HAS, não se verificou diferença significativa após análise } \\
\text { multivariada }\end{array}$ \\
\hline Noordzij et al. ${ }^{30}$ & $\begin{array}{l}1010 \text { indivíduos } \\
\text { Meta-análise de } 16 \text { estudos randomizados }\end{array}$ & $\begin{array}{l}\text { PAS e PAD aumentaram com cafeína isolada e com café, } \\
\text { mas o efeito da cafeína foi maior }\end{array}$ \\
\hline Winkelmayer et al. ${ }^{31}$ & $\begin{array}{l}155594 \mathrm{M} \\
\text { Estudo de coorte prospectivo acompanhado por } \\
12 \text { anos }\end{array}$ & $\begin{array}{l}\text { Nenhuma associação entre consumo de café e incidência de } \\
\text { HAS. Curva em U: associação inversa entre cafeína e HAS }\end{array}$ \\
\hline Andersen et al. ${ }^{32}$ & $\begin{array}{l}41836 \mathrm{M} \\
\text { Estudo de coorte prospectivo acompanhado por } \\
\text { morte atribuída a DCV e doença inflamatória }\end{array}$ & $\begin{array}{l}\text { Relação linear inversa de morte por doença inflamatória e } \\
\text { ingestão de café } \\
\text { Curva em U: associação inversa entre morte por DCV e } \\
\text { ingestão de café }\end{array}$ \\
\hline Uiterwaal et al. ${ }^{33}$ & $\begin{array}{l}2985 \text { H e } 3383 \text { M } \\
\text { Estudo de coorte prospectivo acompanhado por } \\
11 \text { anos }\end{array}$ & $\begin{array}{l}\text { Abstinência de café, mas não o baixo consumo, está associ- } \\
\text { ada ao baixo risco de HAS. Relação inversa entre ingestão de } \\
\text { café e risco de HAS em mulheres }\end{array}$ \\
\hline
\end{tabular}

n: número de sujeitos; H: homens; M: mulheres; PAS: pressão arterial sistólica; PAD: pressão arterial diastólica; HAS: hipertensão arterial sistêmica; DCV: doença cardiovascular. 


\section{Papel do café nas doenças cardiovasculares}

A relação da bebida café com doenças cardiovasculares vem sendo discutida há décadas. Dentre as inúmeras substâncias presentes, destacam-se a cafeína e os diterpenos cafestol e kahweol, compostos relacionados com HAS, inflamação endotelial, IAM, DAC, arritmias cardíacas, acidente vascular cerebral e dislipidemias ${ }^{1,16}$. Destas, hipertensão arterial e dislipidemias são as enfermidades mais comumente pesquisadas.

\section{Café e hipertensão arterial}

A cafeína é a substância do café mais estreitamente relacionada com a pressão arterial. Cerca de $80 \%$ da população mundial consome cafeína diariamente através do café, chás e refrigerantes, sendo o café a fonte mais importante, contribuindo com $71 \%$ da cafeína da dieta dos americanos. Estima-se que uma xícara de $150 \mathrm{~mL}$ de café contenha de 66 a 99mg de cafeína no café infusão, 66 a $81 \mathrm{mg}$ de cafeína no instantâneo, 48 a 86mg de cafeína no fervido, de 58 a $76 \mathrm{mg}$ de cafeína no expresso e de 1,3 a 1,7mg de cafeína no descafeinado ${ }^{5,12}$.

Mais de 99\% da cafeína consumida por via oral é absorvida pelo trato gastrintestinal, atingindo, em sessenta minutos, a corrente sanguínea e, em seguida, exercendo suas ações fisiológicas. Sua principal ação fisiológica é como antagonista da adenosina, um potente neuromodulador endógeno, com efeito, principalmente, inibitório. Em função da semelhança estrutural, a cafeína compete pelos receptores da adenosina produzindo estímulo no Sistema Nervoso Central (SNC), aumento agudo da PA e aumento da velocidade metabólica e da diurese. No sistema cardiovascular, produz aumento agudo do débito cardíaco, vasoconstricção e aumento da resistência vascular periférica. Contrariamente a estes efeitos indesejáveis, alguns estudos in vitro têm demonstrado atividade antioxidante da cafeína ${ }^{1-3,5}$, o que a tornaria um protetor em poten- cial contra os efeitos citados no sistema cardiovascular.

Em revisões recentes ${ }^{1-3,5,24}$ são discutidos diversos estudos experimentais e epidemiológicos que procuraram verificar a associação entre HAS e cafeína; tais estudos concluem por associação positiva, negativa ou nenhuma associação. Estes resultados conflitantes podem ser explicados por diversos vieses, tais como o tabagismo (p. ex. bebedores de café fumam mais), o estresse, o consumo de álcool, a frequência de ingestão da bebida, o status da HAS, a genética, a forma de obtenção do dado de ingestão quantitativa de café, os métodos de preparo, fontes e tipos de café, a presença de substâncias antioxidantes no café e a tolerância à cafeína, entre outros. O Quadro 2 reúne estudos randomizados, meta-análises e estudos de coorte sobre café e níveis de pressão arterial sistêmica ${ }^{25-33}$.

\section{Café e dislipidemias}

Na literatura estão publicados muitos estudos experimentais, clínicos e observacionais que verificaram o efeito do café sobre os lipídeos séricos ${ }^{4,5,19,34-42}$. As substâncias envolvidas são os diterpenos cafestol e kahweol em função dos seus efeitos potencialmente hiperlipemiantes, especialmente sobre o colesterol plasmático. Dentre estes diterpenos, o cafestol apresenta maior potencial de elevação do colesterol, sendo cerca de 80\% por elevação da Lipoproteína de Baixa Densidade (LDL-C; Low Density Lipoprotein Cholesterol) e 20\% por elevação da Lipoproteína de Muito Baixa Densidade (VLDL-C; Very Low Density Lipoprotein Cholesterol)?

Diterpenos, substâncias de natureza lipídica, são encontrados no café torrado e moído, nas formas livre e esterificada com ácidos graxos. Na esterificada, 98\% dos ácidos graxos presentes são: palmítico (16:0), esteárico (18:0), araquídico (20:0), beênico $(22: 0)$, oleico $(18: 1 ; 9)$ e linoleico $(18: 2 ; 9,12)^{43}$. Os diterpenos encontrados no café são: cafestol, kahweol, 16-O-metil-cafestol e 16-O-metil-kahweol, em quantidades que variam 
entre as espécies. O cafestol e o kahweol estão presentes nas duas espécies de café anteriormente citadas, robusta e arábica; destes, o cafestol apresenta-se, em maior concentração na espécie arábica $^{15,43}$. Cafestol e Kahweo/ são os diterpenos que têm despertado maior interesse devido à sua atividade hiperlipemiante ${ }^{35-43}$.

O teor de cafestol e kahweol na bebida varia em função do modo de preparo, ou seja, da técnica culinária de preparação da bebida. O café turco e o fervido, por exemplo, contêm níveis relativamente altos (6 a 12mg/xícara), enquanto o filtrado e o instantâneo contêm níveis baixos $(0,1$ a 0,2mg/xícara), como ilustra o Quadro $3^{1,12}$. O fervido tem maior concentração por causa da alta temperatura empregada durante o preparo e do tempo de contato entre o pó de café e a água.

No Quadro 4 estão selecionados alguns estudos clínicos e epidemiológicos desta década, realizados em humanos, cujo objetivo foi investigar a associação entre ingestão de café e dislipidemia, DAC e IAM ${ }^{4,19,35-42}$. Os estudos convergem para um número de cinco ou mais xícaras de $150 \mathrm{~mL} / \mathrm{dia}^{1,34-37}$ como aquele que categoriza o indivíduo como grande bebedor de café.

\section{Efeito dos diterpenos cafestol e kahweol no metabolismo lipídico}

A possibilidade de elevação das LDL-c e VLDL-c mediante a ingestão de cafestol e kahweol tem sido discutida em diversos estudos publicados, principalmente a partir da década de 199015,18,44-47. Existem três mecanismos propostos que envolvem o cafestol como responsável por mais de $80 \%$ do efeito sobre os lipídeos séricos ${ }^{33,44}$.

O primeiro é o mecanismo mais aceito de elevação das frações LDL-c e VLDL-c, e pode ser explicado por um efeito primário do cafestol sobre a proteína de ligação ao elemento de resposta a esteróides $^{45}$ (SREBP - Sterol Regulatory Element Binding Protein). O cafestol atua inibindo a via da SREBP, que é fator de transcrição ligado a membranas, importante reguladora da biossíntese de colesterol em humanos, uma vez que controla a transcrição dos genes da Hidroxi Metil Glutaril Coenzima A redutase (HMG-CoA redutase), Lipase Lipoproteica (LPL) e dos receptores de LDL (receptores B/E). A diminuição da atividade da SREBP pode, assim, resultar em diminuição da síntese do colesterol e do catabolismo de VLDL e

Quadro 3. Conteúdo de diterpenos cafestol e kahweol no café segundo métodos de preparo da bebida.

\begin{tabular}{|c|c|}
\hline Métodos de preparo do café & $\begin{array}{l}\text { Quantidade de diterpenos } \\
\text { (mg/xícara habitualmente utilizada) }\end{array}$ \\
\hline $\begin{array}{l}\text { Café filtrado: coloca-se o pó no filtro de papel e despeja-se lentamente a água quente sobre } \\
\text { o mesmo. }\end{array}$ & 0,13mg/xícara de $150 \mathrm{~mL}$ \\
\hline Café instantâneo ou solúvel. & 0,26mg/xícara de $150 \mathrm{~mL}$ \\
\hline $\begin{array}{l}\text { Cafeteira italiana ou moca: coloca-se a água na parte inferior de cafeteira, adiciona-se o pó } \\
\text { de café no filtro metálico, que é acoplado ao compartimento inferior. Enroscam-se as duas } \\
\text { partes, inferior e superior, e leva-se ao fogo. Ao ferver a água, o vapor d’água, por pressão, } \\
\text { sobe pelo filtro, passando pela camada de pó. Assim que a água começar a ferver, abaixa-se } \\
\text { o fogo. }\end{array}$ & $3,6 \mathrm{mg} /$ xícara de $60 \mathrm{~mL}$ \\
\hline $\begin{array}{l}\text { Café expresso: coloca-se o pó no filtro próprio e conecta-se à máquina de café expresso por } \\
25 \text { a } 30 \text { segundos. Nesse sistema, é empregada a percolação à alta pressão em } 90^{\circ} \mathrm{C} \text {. }\end{array}$ & 4,1 mg/xícara de $50 \mathrm{~mL}$ \\
\hline $\begin{array}{l}\text { Cafeteira ou expresso francês: adiciona-se o pó de café com a água fervida numa cafeteira } \\
\text { própria. Ao servir, a mistura passa por um coador situado na parte inferior à tampa da } \\
\text { garrafa. }\end{array}$ & 5,6mg/xícara de $150 \mathrm{~mL}$ \\
\hline $\begin{array}{l}\text { Café turco: adiciona-se a água, o açúcar e o pó de café e ferve-se a mistura por } 3 \text { vezes. } \\
\text { Deixa-se repousar a bebida por dois minutos. }\end{array}$ & $8,4 \mathrm{mg} /$ xícara de $60 \mathrm{~mL}$ \\
\hline $\begin{array}{l}\text { Café fervido ou escandinavo: ferve-se a água com o pó de café num recipiente e decanta-se } \\
\text { a bebida num copo. }\end{array}$ & 12,7mg/xícara de $150 \mathrm{~mL}$ \\
\hline
\end{tabular}

Fonte: Higdon \& Frei ${ }^{1}$ e Nakasato et al. ${ }^{12}$. 
em supressão da atividade do receptor $B / E$, aumentando LDL e VLDL séricas. Outros possíveis efeitos do cafestol sobre a SREBP, que merecem destaque, são: 1) a inibição da atividade da acil-CoA colesterol aciltransferase (ACAT; Acyl-coenzime A cholesterol acyltransferase) no hepatócito, inibindo a esterificação do colesterol, disponibilizando colesterol livre para a célula hepática; e, 2) a inibição da atividade da enzima colesterol $7 \alpha$-hidroxilase, reduzindo a conversão do colesterol em ácidos biliares ${ }^{45,47}$. Ao aumentar a concentração de colesterol livre nos hepatócitos por estas duas vias, a atividade da SREBP é suprimida, resultando, mais uma vez, na diminuição da HMG-CoA redutase, LPL e supressão dos receptores B/E e, consequentemente, em elevação de VLDL-c e LDL-c ${ }^{45}$. O mecanismo de atuação das SREBP envolve uma série de cascatas proteolíticas e separações estru-

Quadro 4. Estudos selecionados relacionando ingestão de café e dislipidemias, aterosclerose, IAM e DAC.

\begin{tabular}{|c|c|c|}
\hline Referência & Número e tipo de estudo & Conclusão \\
\hline Jee et al..$^{35}$ & $\begin{array}{l}885 \text { indivíduos } \\
\text { Meta-análise de } 14 \text { estudos } \\
\text { randomizados }\end{array}$ & $\begin{array}{l}\text { Verificaram relação dose-resposta entre o consumo de café e } \\
\text { níveis séricos de colesterol e LDL, sendo o efeito maior nos } \\
\text { portadores de dislipidemia }\end{array}$ \\
\hline Panagiotakos et al. ${ }^{36}$ & $\begin{array}{l}884 \text { indivíduos com história de IAM e } \\
1078 \text { controles } \\
\text { Estudo caso-controle }\end{array}$ & $\begin{array}{l}\text { Associação por curva em J: o consumo moderado }(300 \mathrm{~mL} \\
\text { dia) foi benéfico e o consumo elevado ( }>600 \mathrm{~mL} / \mathrm{dia}) \text { aumen- } \\
\text { tou o risco de IAM }\end{array}$ \\
\hline Hammar et al. ${ }^{38}$ & $\begin{array}{l}1643 \text { indivíduos com história de } \\
\text { IAM e } 2667 \text { controles } \\
\text { Estudo caso-controle }\end{array}$ & $\begin{array}{l}\text { O consumo de café fervido aumenta a incidência de IAM não } \\
\text { fatal }\end{array}$ \\
\hline Happonen et al. ${ }^{37}$ & $\begin{array}{l}1971 \text { homens sem DCV no início } \\
\text { do estudo acompanhados por } 14 \text { anos } \\
\text { Estudo de coorte }\end{array}$ & $\begin{array}{l}\text { Associação por curva em J: o consumo elevado ( }>800 \mathrm{~mL} / \mathrm{dia} \text { ) } \\
\text { aumentou o risco de IAM independente do método de pre- } \\
\text { paro e dos FRCV presentes (tabagismo p. ex), quando com- } \\
\text { parado ao consumo moderado ( } 400-800 \mathrm{~mL} / \mathrm{dia} \text { ) }\end{array}$ \\
\hline Mukamal et al. ${ }^{39}$ & $\begin{array}{l}1902 \text { indivíduos com IAM } \\
\text { acompanhados por } 5 \text { anos. } \\
\text { Estudo de coorte }\end{array}$ & $\begin{array}{l}\text { Não se verificou associação entre o consumo de café e mor- } \\
\text { talidade pós IAM }\end{array}$ \\
\hline Baylin et al..$^{40}$ & $\begin{array}{l}503 \text { indivíduos com história de IAM } \\
\text { acompanhados por } 4 \text { anos } \\
\text { Estudo de coorte }\end{array}$ & $\begin{array}{l}\text { A ingestão de café pode ser um "gatilho" para IAM, princi- } \\
\text { palmente nos indivíduos que consomem pouco ( } \geq 1 \text { xic/dia), } \\
\text { sedentários ou com } \geq 3 \text { FRCV para DAC }\end{array}$ \\
\hline Lopez-Garcia et al. ${ }^{4}$ & $\begin{array}{l}44004 \mathrm{H} \text { e } 84488 \mathrm{M} \text { sem DCV, } \\
\text { acompanhados por } 16 \text { e } 20 \text { anos } \\
\text { Estudo de coorte }\end{array}$ & $\begin{array}{l}\text { Os resultados obtidos não verificaram evidências de que o } \\
\text { consumo de café aumenta o risco de DCV }\end{array}$ \\
\hline Costa et al. ${ }^{19}$ & $\begin{array}{l}60 \text { pacientes com dislipidemia com consumo } \\
\text { moderado de café ( } 250 \mathrm{~mL} \text { água: } 30 \mathrm{~g} \text { pó) } \\
\text { por } 6 \text { semanas } \\
\text { Estudo randomizado. }\end{array}$ & $\begin{array}{l}\text { O consumo moderado de café ( } 250 \mathrm{~mL} / \mathrm{dia} \text { ) filtrado em filtro } \\
\text { de papel ou em coador de pano apresentou efeito protetor } \\
\text { sobre a peroxidação lipídica e nenhum efeito sobre os lipídios } \\
\text { séricos e sobre as enzimas hepáticas }\end{array}$ \\
\hline Silletta et al..$^{41}$ & $\begin{array}{l}9584 \mathrm{H} \text { e } 1644 \text { M com IAM recente, acompa- } \\
\text { nhados por até 3,5 anos. } \\
\text { Estudo de coorte }\end{array}$ & $\begin{array}{l}\text { O consumo de café não aumentou o risco de evento car- } \\
\text { diovascular após IAM }\end{array}$ \\
\hline Sofi et al. ${ }^{42}$ & $\begin{array}{l}\text { Meta-análise de } 13 \text { estudos caso-controle } \\
\text { ( } n=9487 \text { casos e } 27747 \text { controles) e } 10 \text { estudos } \\
\text { de coorte ( } n=403631 \text { indivíduos acompanhados } \\
\text { por } 3 \text { a } 44 \text { anos) }\end{array}$ & $\begin{array}{l}\text { Para os estudos caso-controle verificou-se associação positi- } \\
\text { va entre consumo elevado de café ( } 3 \text { a } 4 \text { e } \geq 4 \text { xic/dia) e DCV. } \\
\text { Para os estudos de coorte não se verificou associação entre } \\
\text { consumo de café e DCV }\end{array}$ \\
\hline
\end{tabular}

n: número de sujeitos; H: homens; M: mulheres; IAM: infarto agudo do miocárdio; FRCV: fatores de risco cardiovascular; DAC: doença arterial coronariana; DCV: doença cardiovascular. 
turais46; apesar da forte plausibilidade biológica deste mecanismo, os resultados de estudos in vitro ainda são conflitantes.

Outro mecanismo hiperlipemiante proposto para o cafestol pode ser explicado pelo aumento da atividade da proteína de transferência de ésteres de colesterol (Cholesterol Ester Transfer Protein - (ETP) e da proteína de transferência de fosfolipídios (Phospholipid Transfer Protein - PLTP), resultando em mudança na composição das lipoproteínas, principalmente o enriquecimento de LDL-c e VLDL-c com ésteres de colesterol, gerando aumento destas duas lipoproteínas e diminuição da lipoproteína de alta densidade (High Density Lipoprotein Cholesterol - HDL-c) circulantes ${ }^{45}$.

O terceiro e último mecanismo que explicaria o efeito do cafestol sobre os triglicerídeos séricos seria por antagonizar a ação do receptor ativado por proliferadores de peroxissomas (PPARPeroxisome Proliferator-Activated Receptor). Os $\operatorname{PPAR}(\alpha, \beta$ e $\gamma)$ constituem uma família de receptores com importantes funções no metabolismo de gorduras, modulados por vários metabólitos e drogas, sendo o PPAR $\alpha$ um receptor-chave na $\beta$-oxidação de ácidos graxos nos peroxissomas, e o PPAR $\gamma$ envolvido na estocagem de ácidos graxos. Há indícios de que o cafestol inibe a transcrição de genes responsáveis pelas três isoformas destes receptores ${ }^{45,48}$.

Segundo De Roos \& Kathan ${ }^{45}$, o mecanismo mais aceito para explicar a elevação do colesterol em humanos é o da via SREBP, embora os estudos in vitro indiquem que o cafestol ou seus metabólitos atuem de forma diferente em diferentes tipos de células, como nas células $\mathrm{CaCo} 2$ (uma linha de células de adenoma de cólon humano), fibroblastos de pele humana, células HepG2 (uma linha de células de hepatoma humano) e células de hepatócitos de ratos. Porém, estas células têm diferentes funções metabólicas, o que poderia explicar os resultados conflitantes dos estudos in vitro ${ }^{45}$. O fato é que são necessários mais estudos in vitro e in vivo, para que se possa conhecer como o cafestol afeta a composição, a síntese e a degradação de lipoproteínas em humanos, e como é transportado no plasma e metabolizado no fígado.

\section{Efeito protetor dos antioxidantes do café}

O desequilíbrio entre a produção de Espécies Reativas de Oxigênio e Nitrogênio (ERON) e as defesas antioxidantes determina o estresse oxidativo, condição relacionada com doenças degenerativas, cardiovasculares e certos tipos de câncer ${ }^{49}$. Dentre o arsenal de defesas antioxidantes (enzimáticas e não enzimáticas) estão aquelas obtidas da dieta, seja atuando 1) indiretamente, como é o caso do selênio, nas glutationas peroxidases, e de zinco e cobre, na superóxido dismutase, ou 2) diretamente, como é o caso dos compostos fenólicos, carotenóides, vitamina C, vitamina E e tiamina.

Estudos clínicos e epidemiológicos têm discutido a importância de substâncias fenólicas (flavonoides e ácidos fenólicos), encontradas em alimentos de origem vegetal, na prevenção de doenças cardiovasculares ${ }^{50,51}$. Segundo Vasconcelos et al. ${ }^{49}$, os flavonoides constituem o maior grupo de compostos fenólicos existentes na natureza e estão amplamente distribuídos nos vegetais. A ingestão de flavonoides pela população brasileira é de 60 a 106mg/dia, quantidade obtida principalmente dos vegetais, tomate, alface e laranja, muito embora o café pertença ao grupo de alimentos com maior conteúdo de antioxidantes ${ }^{52,53}$.

Além da cafeína e dos diterpenos, o café é uma importante fonte de compostos fenólicos não flavonóides (ácidos fenólicos), especialmente de ácidos clorogênicos (formados a partir da esterificação do ácido quínico com ácidos hidrocinâmicos), dos quais o ácido cafeico apresenta a maior capacidade protetora antioxidante, devido à existência de duas hidroxilas nas posições 3 e 4, na sua estrutura química ${ }^{54,55}$. A bebida café apresenta uma quantidade de ácidos clorogênicos que varia, dependendo do estudo, em média, de 70 a 
350mg/xícara de $200 \mathrm{~mL}^{1}$, de 200 a 550mg/xícara de $200 \mathrm{~mL}^{56}$ e $396 \mathrm{mg} / x^{\prime}$ cara de $180 \mathrm{~mL}^{5}$. Apesar desta diversidade de informação na literatura, fruto do tipo de grão, tipo de preparo e técnica de análise, entre outros fatores, o teor de ácidos clorogênicos nesta bebida é apreciável.

Estudos in vitro e clínicos têm evidenciado atividade antioxidante de substâncias presentes no café. Soares ${ }^{54}$, revisando a literatura, cita estudos in vitro realizados em microssomas, eritrócitos, monócitos e em modelos de LDL oxidada, nos quais foi verificada inibição significativa da peroxidação lipídica, devido à atividade antioxidante dos ácidos clorogênicos, atribuída, principalmente, ao ácido cafeico. Silva et al..$^{57}$ verificaram, também in vitro, a presença de compostos fenólicos e o comportamento antioxidante da bebida café, segundo formas de preparo: solúvel, filtrado, à brasileira e expresso, sobre a peroxidação lipídica, utilizando o sistema ácido linoléico/ $\beta$-caroteno. Os autores constataram que o café solúvel apresentou o maior efeito protetor contra a oxidação e a maior efetividade em bloquear as fases de iniciação e propagação da cadeia oxidativa, o que atribuíram ao efeito da diluição.

Dentre os diversos estudos realizados em humanos, que procuraram verificar a atividade antioxidante do café, apresentados em duas revisões ${ }^{5,6}$, destacam-se quatro. Um verificou a presença do antioxidante ácido cafeico, em plasma, $2 \mathrm{~h}$ após a ingestão de café; outro observou um aumento de $7 \%$ na capacidade antioxidante total, que resulta do conjunto de antioxidantes disponíveis no plasma para atuarem como tal; um terceiro verificou um aumento de $16 \%$ nos níveis de glutationa, o maior antioxidante in vivo, fundamental para os processos de óxido-redução das células, com a ingestão de cinco xícaras/dia de café estilo moca (Quadro 3); e, por fim, um outro estudo observou uma diminuição em 30\% da oxidabilidade de LDL, com a ingestão de três xícaras/dia da bebida, indicando uma maior estabilidade desta partícula ao ataque de radicais livres. Estes dados corroboram o efeito protetor do café, discutido na literatura.
Assim, além dos polifenóis, outros compostos presentes no café também teriam atividade antioxidante, como a cafeína, os compostos voláteis responsáveis pelo aroma e os diterpenos cafestol e kahweol, corroborando o status da bebida como uma das maiores fontes de antioxidantes da dieta ${ }^{6}$. Isso explicaria o efeito protetor do consumo de café e os resultados inconclusivos dos estudos que buscaram a associação entre o consumo da bebida e doença cardiovascular.

\section{O N CLUS Ã O}

A composição do café e sua repercussão sobre a saúde humana, notadamente sobre as doenças cardiovasculares, vêm sendo objeto de muitos estudos, cujos resultados são conflitantes. Tal fato, provavelmente, se deve à presença de substâncias com efeitos antagônicos em potencial, ou seja, ao mesmo tempo antioxidantes e com potencial para a elevação do colesterol sérico e para o aumento agudo da pressão arterial sistêmica. Portanto, são necessários mais estudos experimentais, clínicos e epidemiológicos para determinar o efeito que prevalece em diferentes contextos. No momento, a tendência é considerar o consumo moderado da bebida como inócuo ou com efeito modesto sobre o risco cardiovascular, senão protetor, traduzindo-se em uma prática benéfica para a saúde humana.

\section{COLABORADORES}

F.A. LIMA participou da redação do artigo. S.M.L. VASCONCELOS orientou o trabalho, definiu a estrutura e liderou a redação do artigo. A.E.G. SANT'ANA, T.R. ATAIIDE, C.M.B. OMENA e E.M.S. MENEZES contribuíram na redação do artigo.

\section{REFERÊ NCIAS}

1. Higdon JV, Frei B. Coffee and health: a review of recent human research. Crit Rev Food Sci Nutr. 2006; 46:101-23.

2. Hamer M. Coffee and health: explaining conflicting results in hypertension. J Hum Hypertens. 2006; 20:909-12. 
3. Sudano I, Binggeli C, Spieker L, Luscher TF, Ruschitzka F, Noll G, et al. Cardiovascular effects of coffee: is it a risk factor? Prog Cardiovasc Nurs. 2005; 20:65-9.

4. Lopez-Garcia E, Van Dam RM, Willett WC, Rimm EB, Manson JE, Stampfer MJ, et al. Coffee consumption and coronary heart disease in men and women. Circulation. 2006; 113:2045-53.

5. Bonita JF, Mandarano M, Shuta D, Vinson J. Coffee and cardiovascular disease: in vitro, cellular, animal, and human studies. Pharmacol Res. 2007; 55: 187-98.

6. Dórea JG, Costa THM. Is coffee a functional food? Br J Nutr. 2005; 93:773-82.

7. Van Dam RM, Willet WC, Manson JE, Hu FB. Coffee, caffeine, and risk of type 2 diabetes. Diabetes Care. 2006; 29:398-403.

8. Pereira MA, Parker ED, Folsom AR. Coffee consumption and risk of type 2 diabetes mellitus. Arch Intern Med. 2006; 166:1311-16.

9. Van Dam RM. Coffee and type 2 diabetes: from beans to beta-cells. Nutr Metabol Cardiovasc Dis. 2006; 16:69-77.

10. Greenberg JA, Boozer CN, Geliebter A. Coffee, diabetes and weight control. Am J Clin Nutr. 2006; 84:682-93.

11. Ruhl CE, Everhart JE. Coffee and tea consumption are associated with a lower incidence of chronic liver disease in the United States. Gastroenterology. 2005; 129:1928-36.

12. Nakasato M, Giorgi DMA, Isosaki M. Mitos e verdades sobre o café e doenças do coração. Rev Soc Cardiol Estado de São Paulo. 2001; 11(6):13-20.

13. Monteiro MC, Trugo LC. Determinação de compostos bioativos em amostras comerciais de café torrado. Quim Nova. 2005; 28(4):637-41.

14. Moreira RFA, Trugo LC, De Maria CAB. Componentes voláteis do café torrado. Parte II: compostos alifáticos, alicíclicos e aromáticos. Quim Nova. 2000; 23(2):195-203.

15. Masten S, Tice R. Cafestol and kahweol. Review of toxicological literature. Research Triangle Park (NC): ILS; 1999 p.2-39.

16. Lancaster T, Muir J, Silagy $C$. The effects of coffee on serum lipids and blood pressure in a UK population. J Royal Soc Medicine. 1994; 87:506-7.

17. Dusseldorp MV, Katan BM, Van Vliet T, Demacker PNM, Stalenhoef AFH. Cholesterol-raising factor from boiled coffee does not pass a paper filter. Arterioscler Thromb. 1991; 11:586-93.

18. Zock PL, Katan MB, Merkus MP, Dusseldorp MV, Harryan JL. Effect of a lipid-rich fraction from boiled coffee on serum cholesterol. Lancet. 1990; 335: 1235-37.
19. Costa RP, Izar MCO, Elias MC, Ihara SSM, Santos AO, Pinto LESA, et al. Moderate comsumption of drip paper-filtered or boiled and cotton-filtered coffee does not affect lipid profile, and improves lipid peroxidation in patients with primary hypercholesterolemia. Int J Atheroscler. 2006; 1(2): 149-55.

20. Brasil. Associação Brasileira da Indústria do Café (ABIC). [acesso 2008 jan 17]. Disponível em: <http:// www.abic.com. br/>.

21. De Maria CA, Moreira RFA, Trugo LC. Componentes voláteis do café torrado. Parte I: compostos heterocíclicos. Quim Nova. 1999; 22(2):209.

22. Fernandes SM, Pinto NAVD, Thé PMP, Pereira RGFA, Carvalho VD. Teores de polifenóis, ácido clorogênico, cafeína e proteína em café torrado. Rev Bras de Agrociência. 2001; 7(3):197-99.

23. Núcleo de Estudos e Pesquisa em Alimentação. Tabela Brasileira de Composição de Alimentos (TACO); versão II. Campinas: Flamboyant; 2006.

24. Jack $E$, James $E$. Critical review of dietary caffeine and blood pressure: a relationship that should be taken more seriously. Psychosom Med. 2004; 66: 63-71.

25. Birkett NJ, Logan AG. Caffeine-containing beverages and the prevalence of hypertension. J Hypertens. 1988; 6(4):S620-22.

26. Stensvold I, Tverdal A, Foss OP. The effect of coffee on blood lipids and blood pressure. Results from a Norwegian cross-sectional study, men and women, 40-42 years. J Clin Epidemiol. 1989; 42:877-84.

27. Jee SH, He J, Whelton PK, Suh L, Klag M. The effect of chronic coffee drinking on blood pressure: a meta-analysis of controlled clinical trials. Hypertension. 1999; 33:647-52.

28. Hartley TR, Sung BH, Pincomb GA, Whitsett TL, Wilson MF, Lovallo WR. Hypertension risk status and effect of caffeine on blood pressure. Hypertension. 2000; 36:137-41.

29. Klag MJ, Wang NY, Meoni LA, Brancati FL, Cooper LA, Liang KY, et al. Coffee intake and risk of hypertension. Arch Int Med. 2002; 162:657-62.

30. Noordzij M, Uiterwaal CS, Arends LR, Kok FJ, Grobbee DE, Geleijnse JM. Blood pressure response to chronic intake of coffee and caffeine: a metaanalysis of randomized controlled trials. J Hypertens. 2005; 23:921-8.

31. Winkelmayer WC, Stampfer MJ, Willett WC, Curhan GC. Habitual caffeine intake and risk of hypertension in women. JAMA. 2005; 294(18): 2330-35. 
32. Andersen LF, Jacobs Jr DR, Carlsen MH, Blomhoff R. Consumption of coffee is associated with reduced risk of death attributed to inflammatory and cardiovascular diseases in the lowa Women's Health Study. Am J Clin Nutr. 2006; 83:1039-46.

33. Uiterwaal CSPM, Verschuren WM, Bueno-deMesquita HB, Ocké M, Geleijnse JM, Boshuizen HC, et al. Coffee intake and incidence of hypertension. Am J Clin Nutr. 2007; 85:718-23.

34. Urgert R, Katan MB. The cholesterol-rasing factor from coffee beans. Ann Rev Nutr. 1997; 17:305-24.

35. Jee SH, He J, Appel L, Whelton PK, Suh II, Klag MJ. Coffee consumption and serum lipids: a metaanalysis of randomized controlled clinical trials. Am J Epidemiol. 2001; 153(3):353-62.

36. Panagiotakos DB, Pitsavos C, Chrysohoou C, Kokkinos P, Toutouzas P, Stefanadis C. The J-shaped effect of coffee consumption on the risk of developing acute coronary syndromes: the CARDIO2000 case-control study. J Nutr. 2003; 133: 3228-32.

37. Happonen P, Voutilainen S, Salonen JT. Coffee drinking is dose-dependently related to the risk of acute coronary events in middle-aged men. J Nutr. 2004; 134:2381-6.

38. Hammar N, Andersson T, Aldredsson L, Reuterwall C, Nilsson T, Hallqvist J, et al. SHEEP and the VHEEP study. Association of boiled filtered coffee with incidence of first nonfatal myocardial infarction:the SHEEP and the VHEEP study. J Intern Med. 2003; 253:653-9.

39. Mukamal KJ, Maclure M, Muller JE, Sherwood JB, Mittleman MA. Caffeinated coffee consumption and mortality after acute myocardial infarction. Am Heart J. 2004; 147:999-1004.

40. Baylin A, Hernandez-Diaz S, Kabagambe EK, Siles $\mathrm{X}$, Campos H. Transient exposure to coffee as a trigger of a first nonfatal myocardial infarction. Epidemiology. 2006; 17:506-11.

41. Silletta MG, Marfisi RM, Levantesi G, Boccanelli A, Chieffo C, Fransozi MG, et al. Coffee consumption and risk of cardiovascular events after acute myocardial infarction. Circulation. 2007; 116 : 2944-51.

42. Sofi F, Conti AA, Gori AM, Eliana Luisi ML, Casini A, Abbate $\mathrm{M}$, et al. Coffee and consumtion and risk of coronary heart disease: a meta-analysis. Nutr Metab Cardiovasc Dis. 2007; 17(3):209-23.

43. Speer K, Kolling-Speer I. The lipid fraction of the coffee bean. Braz J Plant Physiol. 2006; 18(1):201-16.

44. Gross G, Jaccaud E, Huggett AC. Analysis of the content of the diterpenes cafestol and kahweol in coffee brews. F Chem Toxic. 1997; 35:547-54.
45. De Roos B, Katan MB. Possible mechanisms underlying the cholesterol-raising effect of the coffee diterpene cafestol. Curr Opin Lipidol. 1999; 10:41-5.

46. Brown MS, Goldstein JL. The SREBP pathway: regulation of cholesterol metabolism by proteolysis of a membrane-bound transcription factor. Cell. 1997, 89:331-40.

47. Boekschoten MV, Hofman MK, Buytenhek R, Schouten EG, Princen HMG, Katan MB. Coffee oil consumption increases plasma levels of 7 $\alpha$-hydroxy-4-cholesten-3-one in humans. J Nutr. 2005;135(4):785-9.

48. Schoonjans K, Staels B, Auwerx J. The peroxisome proliferator activated receptors (PPARs) and their effects on lipid metabolism and adipocyte differentiation. Biochim Biophys Acta. 1996; 1302: 93-102.

49. Vasconcelos SML, Silva MAM, Goulart MOF. Pró-antioxidantes e antioxidantes de baixo peso molecular oriundos da dieta: estrutura e função. Nutrire. 2006; 31(3); 95-118.

50. Hu FB, Willett WC. Optimal diets for prevention of coronary heart disease. JAMA. 2002; 288:2569-78.

51. Hu FB. Plant-based foods and prevention of cardiovascular disease: an overview. Am J Clin Nutr. 2003; 78(Suppl 1):S544-S51.

52. Pietta PG. Flavonoids as antioxidants. J Nat Prod. 2000; 63:1035-42.

53. Arabbi PR, Genovese MI, Lajolo FM. Flavonoids in vegetable foods commonly consumed in Brazil and estimated ingestion by the brazilian population. J Agric Food Chem. 2004; 52:1124-31.

54. Soares SE. Ácidos fenólicos como antioxidantes. Rev Nutr. 2002; 15(1):71-81. doi: 10.1590/S1415-52 732002000100008.

55. Farah A, Donangelo CM. Phenolic compounds in coffee. Braz J Plant Physiol. 2006; 18(1):23-36.

56. Natella F, Nardini M, Belelli F, Scaccini C. Coffee drinking induces incorporation of phenolic acids into $L D L$ and increases the resistance of LDL to ex vivo oxidation in humans. Am J Clin Nutr. 2007; 86: 604-9.

57. Silva DCF, Nascimento MA, Moreira AVB. Verificação da presença de compostos fenólicos com propriedades antioxidantes em amostras de café. J Braz Soc Food Nutr. 2007; 32(1):23-40.

Recebido em: 11/1/2009

Versão final reapresentada em: 3/11/2009 Aprovado em 13/5/2010 
